\title{
In reply: an example of the evolution of evidence in a new disease
}

\author{
Benjamin Condon*1,2,3 (iD), Thomas Whish-Wilson ${ }^{3,4,5}$ (D), Niall F. Davis ${ }^{6,7}$ (D) \& Nathan \\ Lawrentschuk ${ }^{1,2,8}$ iD \\ ${ }^{1}$ Peter MacCallum Cancer Centre, Division of Surgery, Melbourne, Australia \\ 2E.J. Whitten Prostate Cancer Research Centre at Epworth, Victoria, Australia \\ ${ }^{3}$ University of Melbourne, Melbourne, Australia \\ ${ }^{4}$ Department of Urology, Austin Health, Melbourne Australia \\ ${ }^{5}$ St Vincent's Hospital Melbourne, Department of Urology, Melbourne, Australia \\ ${ }^{6}$ Department of Urology, Beaumont Hospital, Dublin, Ireland \\ ${ }^{7}$ Department of Surgery, The Royal College of Surgeons in Ireland, Dublin, Ireland \\ ${ }^{8}$ Department of Urology, Royal Melbourne Hospital, Melbourne, Australia \\ *Author for correspondence: bencondon34@gmail.com
}

First draft submitted: 29 August 2020; Accepted for publication: 2 September 2020; Published online: 4 December 2020

We write to acknowledge and thank Kunz et al. for their Letter to the Editor 'Cave canem: Urine is not urine in corona times' [1] responding to our article 'Implication of COVID-19 on urological laparoscopic surgery' [2]. In particular, we appreciate the point that current evidence suggests a possible infectious hazard within urine, which is in contrast to our original publication. As we continue to understand more about the SARS-CoV-2, it is important to acknowledge the rapidly growing evidence base in the literature, and this is a perfect example.

Kunz et al. identify the percentage of SARS-CoV-2 being isolated in urine as roughly $3 \%$ of tested patients from a combined six studies $(n=13 / 142)$ [1,3-8]. Despite the relatively low percentage and several studies failing to isolate SARS-CoV-2 in urine, it is important to recognize the potential risks for urologists, which should not be understated, particularly in the creation of surgical guidelines. Kunz et al.'s critique of several studies [9-14] that failed to identify any positive urine samples as resulting from low sample analysis, unclear methodological quality or lacking data on temperature and both time of the sample assessment and time after disease onset as factors related to the discordant findings within the literature that informed our original publication [1]. Nevertheless, it is clear that urine is not urine, and reliance on its sterility is no more! We support Kunz et al.'s contention that our previous reassurance was misplaced and also endorse the EAU-Guidelines on COVID-19 [15].

Although the physiological mechanisms of SARS-CoV-2's detectability in urine remain uncertain, we read with interest Kunz et al.'s discussion on its affinity for the ACE2 receptor, which is found within the human kidney, and the importance of recognizing the role of organ tropisms in viral elimination, disease progression or fatality rate $[16,17]$. Of note is the possibility that urinary excretion of SARS-CoV-2 could be dependent on the infection cycle or severity of tissue damage. In particular, acute kidney injury may be an independent risk factor for predicting hospital in-patient mortality [18], and therefore SARS-CoV-2 viral particles may be detectable in the urine as a result of renal damage $[19,20]$.

The global effort to understand SARS-CoV-2 and work to ensure the safety of both providers and patients continues to prove dynamic. We thank Kunz et al. for their letter to the editor and for demonstrating the need for constant reevaluation in this rapidly evolving landscape.

Financial \& competing interests disclosure

The authors have no relevant affiliations or financial involvement with any organization or entity with a financial interest in or financial conflict with the subject matter or materials discussed in the manuscript. This includes employment, consultancies, honoraria, stock ownership or options, expert testimony, grants or patents received or pending, or royalties.

No writing assistance was utilized in the production of this manuscript.

Future Medicine 


\section{Reference}

1. Kunz Y, Horninger W, Pinggera GM. Cave canem: urine is not urine in corona times. Future Oncol. 163528992902 2020).

2. Condon B, Whish-Wilson T, Davis NF, Lawrentschuk N. Implications of COVID-19 on urological laparoscopic surgery. Future Oncol. 16(26), 1941-1945 (2020).

3. Kim J-M, Kim HM, Lee EJ et al. Detection and isolation of SARS-CoV-2 in serum, urine, and stool specimens of COVID-19 patients from the Republic of Korea. Osong Public Health Res. Perspect. 11(3), 112-117 (2020).

4. Ling Y, Xu S-B, Lin Y-X et al. Persistence and clearance of viral RNA in 2019 novel coronavirus disease rehabilitation patients. Chin. Med. J. (Engl.) 133(9), 1039-1043 (2020).

5. Peng L, Liu J, Xu W et al. SARS-CoV-2 can be detected in urine, blood, anal swabs, and oropharyngeal swabs specimens. J. Med. Virol. 92(9), 1676-1680 (2020).

6. Wang $\mathrm{L}, \mathrm{Li}$ X, Chen $\mathrm{H}$ et al. Coronavirus disease 19 Infection does not result in acute kidney injury: an analysis of 116 hospitalized patients from Wuhan, China. Am. J. Nephrol. 51(5), 343-348 (2020).

7. Zhang J, Wang S, Xue Y. Fecal specimen diagnosis 2019 novel coronavirus-infected pneumonia. J. Med. Virol. 92(6), 680-682 (2020).

8. Zheng S, Fan J, Yu F et al. Viral load dynamics and disease severity in patients infected with SARS-CoV-2 in Zhejiang province, China, January-March 2020: retrospective cohort study. BMJ 369, m1443 (2020).

9. Cai J, Xu J, Lin D et al. A case series of children with 2019 novel coronavirus infection: clinical and epidemiological features. Clin. Infect. Dis. 71(6), 1547-1551 (2020).

10. Chan JF-W, Yuan S, Kok K-H et al. A familial cluster of pneumonia associated with the 2019 novel coronavirus indicating person-to-person transmission: a study of a family cluster. Lancet 395(10223), 514-523 (2020).

11. Kujawski SA, Wong KK, Collins JP et al. Clinical and virologic characteristics of the first 12 patients with coronavirus disease 2019 (COVID-19) in the United States. Nat. Med. 26(6), 861-868 (2020).

12. Lescure F-X, Bouadma L, Nguyen D et al. Clinical and virological data of the first cases of COVID-19 in Europe: a case series. Lancet Infect. Dis. 20(6), 697-706 (2020).

13. Lo IL, Lio CF, Cheong HH et al. Evaluation of SARS-CoV-2 RNA shedding in clinical specimens and clinical characteristics of 10 patients with COVID-19 in Macau. Int. J. Biol. Sci. 16(10), 1698-1707 (2020).

14. Wölfel R, Corman VM, Guggemos W et al. Virological assessment of hospitalized patients with COVID-2019. Nature 581(7809), 465-469 (2020).

15. Group EGORR. An organisation-wide collaborative effort to adapt the EAU guidelines recommendations to the COVID-19 era. 2020.

16. Su H, Yang M, Wan C et al. Renal histopathological analysis of 26 postmortem findings of patients with COVID-19 in China. Kidney Int. 98(1), 219-227 (2020).

17. Varga Z, Flammer AJ, Steiger P et al. Endothelial cell infection and endotheliitis in COVID-19. Lancet 395(10234), 1417-1418 (2020).

18. Li W, Moore MJ, Vasilieva N et al. Angiotensin-converting enzyme 2 is a functional receptor for the SARS coronavirus. Nature 426(6965), 450-454 (2003).

19. Perico L, Benigni A, Remuzzi G. Should COVID-19 concern nephrologists? Why and to what extent? The emerging impasse of angiotensin blockade. Nephron 144(5), 213-221 (2020).

20. Valizadeh R, Baradaran A, Mirzazadeh A, Bhaskar LVKS. Coronavirus-nephropathy; renal involvement in COVID-19. J. Renal Inj. Prev. 9(2), e18 (2020). 